\title{
Surgical repair and follow-up of chronic 4th degree obstetric perineal tear (total perineal defect) in 2 centres in eastern Africa
}

\author{
Judith T. W. Goh ${ }^{1,2}$ (1) $\cdot$ Harriet Natukunda ${ }^{3}$. Isaac Singasi ${ }^{3} \cdot$ Emma Kabugho $^{3} \cdot$ Andrew Browning $^{4}$. \\ Hannah G. Krause ${ }^{1}$
}

Received: 10 February 2021 / Accepted: 3 May 2021 / Published online: 18 May 2021

(C) Crown 2021

\begin{abstract}
Introduction and hypothesis Fourth-degree perineal tear occurs in up to $0.2 \%$ of vaginal deliveries. In limited resource communities, women often deliver in local villages without facilities to repair obstetric anal sphincter injuries. These fourth-degree tears heal by secondary intention and result in total perineal defects. The aim of the study is to present medium-term follow-up of a large number of women following repair of chronic fourth-degree tear.

Methods Repairs of chronic obstetric fourth-degree tears were undertaken during surgical camps at Kagando Hospital, Uganda and Selian Hospital, Tanzania, from December 2013 to October 2019. Women completed Cleveland Clinic Incontinence Scores (CCIS) on admission (face to face) and during the 7-year follow-up period (via telephone).

Results Two hundred fourteen women had medical history and CCIS completed on admission. The mean age at presentation was 33.9 years and mean duration of the condition was 8.9 years. Over a third of women stated they suffered social abandonment because of the unrepaired fourth-degree tear. Nearly $45 \%$ of women suffered the tear during the first vaginal delivery. At 1-year follow-up, $87 \%$ of 101 women scored 0 (perfect continence) and $94 \%$ of 66 women had perfect continence at 2 years. Forty-one births occurred during the follow-up period (32 vaginal deliveries) with two recurrences of fourth-degree tear.

Conclusions Follow-up in limited resource communities is challenging. Short- to medium-term results of women who had repair of total perineal defect (unrepaired fourth-degree obstetric tears) are encouraging.
\end{abstract}

Keywords Fourth-degree perineal tear $\cdot$ Total perineal defect $\cdot$ Follow-up

\section{Introduction}

Obstetric anal sphincter injuries (OASIs) occur in 1-9\% of all vaginal deliveries $[1,2]$ and the rates of fourthdegree perineal tear vary between $0.03-0.2 \%$ of all vaginal deliveries [3-6]. In high-resource communities, the fourth-degree tears are diagnosed at time of delivery and local institution protocols are readily available for their management and repair. However, in many parts of the

Judith T. W. Goh

jtwgoh@hotmail.com

1 Greenslopes Private Hospital, Suite 209, Ramsay Specialist Centre, Brisbane, QLD 4120, Australia

2 Griffith University, Gold Coast, Australia

3 Kagando Hospital, Kagando, Uganda

4 Barbara May Foundation, Bowral, NSW, Australia world, women deliver in local villages with no facilities for emergency obstetric services or infrastructures available to repair obstetric anal sphincter injuries. These fourth-degree tears heal by secondary intention, resulting in total perineal defects [7].

Various surgical techniques have been described for the treatment of the unrepaired fourth-degree tear with a "cloacal-type" deformity [8-13]. These vary significantly from routine faecal diversion to use of large tissue flaps.

Previously, we presented our technique for the repair of the chronic fourth-degree tear without tissue flaps or faecal diversions, together with short-term follow-up [14]. In the shortterm follow-up, a smaller group of women were followed up for up to 12 months following repair of the chronic fourthdegree tear.

The aim of this study is to present longer follow-up of our surgical technique. We believe that this is the largest cohort for follow-up of repair of chronic fourthdegree tears. 


\section{Methods}

The study was undertaken during surgical camps (for fistula and pelvic organ prolapse) from December 2013 to October 2019 at the Kagando Hospital, Kasese District, western Uganda (JG, HK), at the foothills of the Rwenzori Mountains and January 2015 to June 2016 at the Selian Hospital, Arusha, Tanzania (AB). There was no local ethics committee at the hospitals. Approval was obtained from the ethics committee at the Greenslopes Private Hospital (protocol 13/46) and is registered on the Australian New Zealand Clinical Trial Registry (ACTRN 12617001520325).

All women with an unrepaired fourth-degree obstetric perineal tear (total perineal defect) [7] (Fig. 1) were invited to participate in the study and were assessed in the outpatient clinic. The examination findings, procedure, risks and postoperative care were explained to the women by local nursing staff in the woman's dialect. Patient demographics were recorded as part of their routine history. Most women were illiterate and could not sign the consent form; hence, their thumbprints were used.

The Cleveland Clinic Continence score (CCIS) was completed preoperatively, at 6 months postoperatively and then at yearly intervals. The CCIS utilizes five domains with a score of 0 to 4 for each domain (Table 1). Thus, the score ranges from 0 to 20, where a score of 0 indicates perfect anal continence and a score of 20 indicates total anal incontinence.

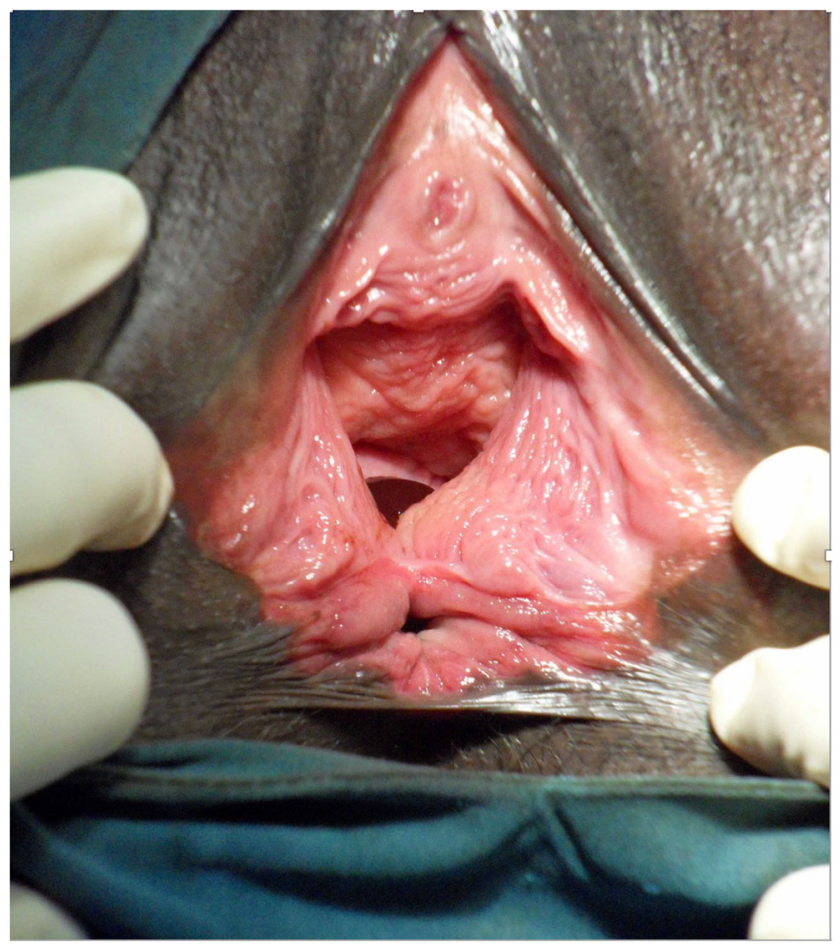

Fig. 1 Chronic fourth-degree tear with fusion of anorectal mucosa to vagina and perineal body skin. The perineal body is absent and the tear extends a few centimetres up the vagina and rectum
In this study, the question on the use of pads for stool leakage was deleted from our questionnaire as pads are not used or not readily available in these districts. If available, pads would be unaffordable for most as the daily income for a family in these areas < US\$2 a day. In our study, the questionnaire was modified to 4 questions; hence, the maximum score was 16 instead of 20. In this study, therefore, the score ranged from 0 to 16 .

All CCISs were collected verbally, at admission and follow-up by telephone interviews. The CCISs were collected by experienced fistula nurses in the local language. Women did not return to the hospital following discharge because of the cost of travel or fear for personal safety during travel or because they did not receive permission from their families.

All procedures were performed under spinal anaesthesia with preoperative bowel preparation and without bowel diversion. As opposed to many other techinques described, no flaps are utilized. The woman was placed in the lithotomy position, and incisions are made on the edge of the fistula, where the anorectal mucosa, vaginal and perineal skin have fused following the obstetric injury. The anorectum is mobilized off the vagina and torn remnants of the external anal sphincter are identified and mobilized. The tissues are closed in layers (anorectal mucosa, overlapping external anal sphincter repair, closure of the vaginal epithelium and reconstruction of the perineal body and skin without drainage) (Fig. 2). An indwelling catheter and vaginal pack were left in situ for 2 days. All women had daily perineal wash and were examined on day 3 after removal of the catheter and vaginal pack; bowels were opened prior to discharge. Aperients were given after day 3 if the bowels had not opened spontaneously. The short-term follow-up of the first 68 women at Kagando Hospital, Uganda, has already been published [14].

\section{Results}

A total of 221 women had repair of the chronic fourth-degree tear. CCISs were incomplete in seven women, who were excluded from the study.

Of the 214 women who completed the CCIS, the median age at presentation was 32 (range 16-80) years (1 woman could not remember her age) and mean parity at presentation was 4.8 (range 1-11). The mean age at first delivery was 18 years (range 13-29; 5 women could not remember). The mean duration of the condition prior to presentation for surgery was 8.9 years (range 1 month-58 years; median 60 months) with $35 \%$ of women having had the injury for $\leq$ 12 months.

One hundred forty-two women responded as to whether they were sexually active. Of the 142 women, 89 (62.7\%) were sexually active and $58.8 \%$ of women who were sexually active complained of dyspareunia. Information on social 
Table 1 Follow-up Cleveland Clinic Incontinence scores

\begin{tabular}{|c|c|c|c|c|c|c|c|c|c|}
\hline Follow-up after surgery & $\begin{array}{l}\text { Pre-op } \\
(n=214)\end{array}$ & $\begin{array}{l}6 \text { months } \\
(n=171)\end{array}$ & 1 year $(n=101)$ & $\begin{array}{l}2 \text { years } \\
(N=66)\end{array}$ & 3 years $(n=36)$ & $\begin{array}{l}4 \text { years } \\
(n=30)\end{array}$ & $\begin{array}{l}5 \text { years } \\
(n=21)\end{array}$ & $\begin{array}{l}6 \text { years } \\
(n=6)\end{array}$ & $\begin{array}{l}7 \text { years } \\
(\mathrm{n}=6)\end{array}$ \\
\hline \multicolumn{10}{|l|}{ Solid stool leakage } \\
\hline Never & 12 & 171 & 98 & 64 & 36 & 29 & 21 & 5 & 6 \\
\hline$<1 \times /$ month & 50 & 0 & 0 & 2 & 0 & 0 & 0 & 1 & 0 \\
\hline$<1 \times /$ week & 54 & 0 & 2 & 0 & 0 & 1 & 0 & 0 & 0 \\
\hline$<1 \times$ day & 31 & 0 & 0 & 0 & 0 & 0 & 0 & 0 & 0 \\
\hline Everyday & 67 & 0 & 1 & 0 & 0 & 0 & 0 & 0 & 0 \\
\hline \multicolumn{10}{|l|}{ Liquid stool leakage } \\
\hline Never & 0 & 171 & 92 & 64 & 31 & 27 & 18 & 3 & 6 \\
\hline$<1 \times /$ month & 18 & 0 & 4 & 1 & 4 & 2 & 2 & 3 & 0 \\
\hline$<1 \times /$ week & 53 & 0 & 3 & 1 & 1 & 1 & 1 & 0 & 0 \\
\hline$<1 \times /$ day & 31 & 0 & 1 & 0 & 0 & 0 & 0 & 0 & 0 \\
\hline Everyday & 112 & 0 & 1 & 0 & 0 & 0 & 0 & 0 & 0 \\
\hline \multicolumn{10}{|l|}{ Gas leakage } \\
\hline Never & 0 & 168 & 90 & 63 & 31 & 27 & 18 & 4 & 4 \\
\hline$<1 \times /$ month & 0 & 3 & 3 & 0 & 3 & 0 & 1 & 1 & 0 \\
\hline$<1 \times /$ week & 10 & 0 & 4 & 1 & 2 & 3 & 2 & 0 & 2 \\
\hline$<1 \times /$ day & 15 & 0 & 3 & 1 & 0 & 0 & 0 & 0 & 0 \\
\hline Everyday & 189 & 0 & 1 & 1 & 0 & 0 & 0 & 1 & 0 \\
\hline \multicolumn{10}{|l|}{ Lifestyle restriction } \\
\hline Never & 0 & 171 & 95 & 65 & 33 & 29 & 19 & 5 & 6 \\
\hline$<1 \times /$ month & 60 & 0 & 3 & 1 & 3 & 0 & 1 & 1 & 0 \\
\hline$<1 \times /$ week & 25 & 0 & 2 & 0 & 0 & 0 & 1 & 0 & 0 \\
\hline$<1 \times /$ day & 34 & 0 & 0 & 0 & 0 & 1 & 0 & 0 & 0 \\
\hline Everyday & 95 & 0 & 1 & 0 & 0 & 0 & 0 & 0 & 0 \\
\hline
\end{tabular}

status was available in 141 women. Fifty-nine of these 141 women stated that they had been abandoned by their husbands or divorced because of the unrepaired fourth-degree tear.

The women were also asked which delivery caused the fourth-degree tear. One hundred seventy women recalled and could answer the question. The first vaginal delivery caused the fourth-degree tear in $44.7 \%$ of women, second delivery in $12.4 \%$ of women, third delivery in $11.8 \%$, fourth delivery in $10 \%$, fifth delivery in $8.8 \%$ and the sixth to ninth delivery in the remaining women.

Nearly $60 \%$ of women had not sought assistance prior to presentation of whom $40 \%$ cited financial constraints. Others did not know that the condition could be treated (until they heard the radio announcements for the camps saying that the service was available without charge) or provided no reason. Of the $40 \%$ of women who had previously sought assistance, nearly half were told by the health care centre or local advisor that treatment was unavailable or were given medications or herbs.

A modified CCIS was utilized in this study (Table 1). The mean preoperative score was 11.7 (range 2-16). The mean flatal incontinence score was 3.9, mean faecal soiling score was 3.5, mean solid stool incontinence was 2.9 and mean score for lifestyle restriction was 3.5. Over $50 \%$ of women complained of daily faecal soiling.
Postoperatively, of the 214 women, 3 had a wound breakdown requiring further surgery and 1 had a wound haematoma requiring evacuation on day 2 post-operation. One of the three women with wound breakdown had a complete perineal body dehiscence and repeat surgery was performed several weeks later with no complications. The other two women with breakdowns were re-operated within 3 days of their initial surgery and recovered well as did the woman with the evacuation of haematoma.

The follow-up CCIS are summarized in Table 1. At 6month follow-up, CCIS was available for 171 women of whom 168 scored 0 . Three women complained of flatal incontinence, each with a score of 1 .

At 12-month follow-up, 101 women were able to be contacted. Eighty-eight women had a CCIS of 0,10 scored $\leq 4,2$ women scored 5-9 and 1 woman with advanced stage bowel cancer scored 16. The woman with bowel cancer gave no history of suspicious bowel symptoms preoperatively. Flatal loss (12.9\%) was the most common complaint, followed by faecal soiling (liquid stool leakage) $(8.9 \%)$ and faecal incontinence (solid stool leakage) (3\%). Ninety-two women responded to the sexual activity question. Eighty-two women did not have any pain on sexual intercourse while nine complained of dyspareunia. Among those with dyspareunia, five noted slight or mild discomfort. Two women had 


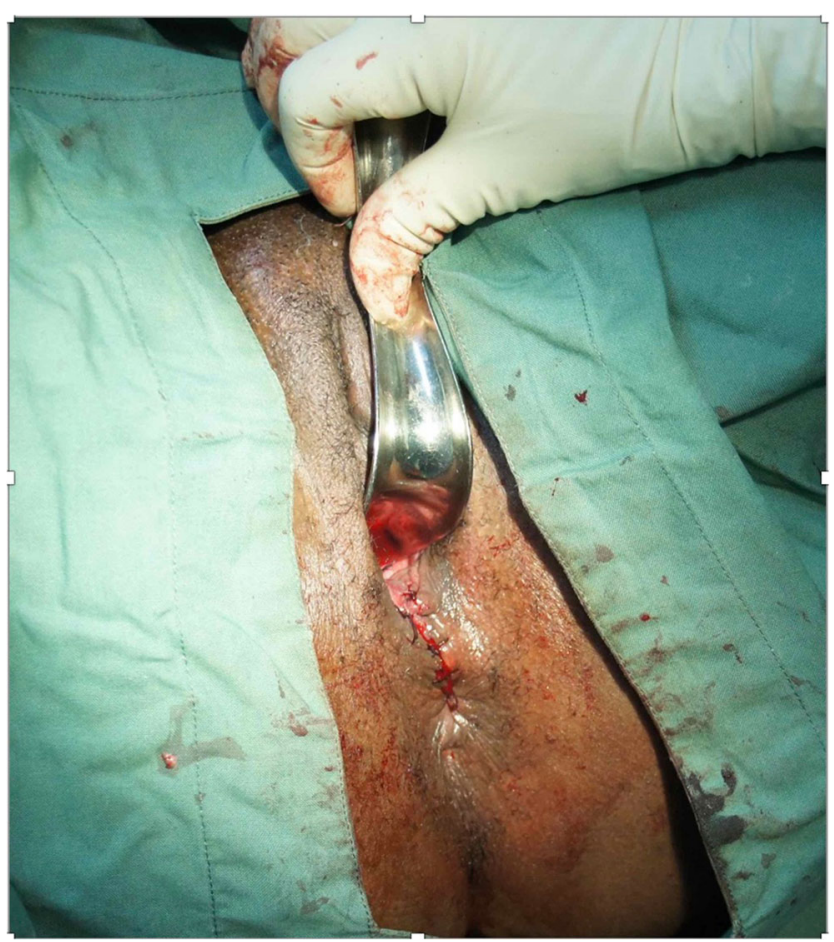

Fig. 2 Completion of the repair with reconstruction of the anal sphincter and perineal body and repair of the vagina without the use of tissue flaps. A Sims speculum is supporting the anterior vaginal wall

subsequent vaginal deliveries without worsening of their anal continence and two other women were pregnant at time of follow-up.

None of the women $(n=29)$ from Tanzania were followed up for $>12$ months. Sixty-six Ugandan women were able to be contacted for 2-year follow-up of whom 62 had a CCIS of 0 . Three women complained of flatal incontinence (score 2, 3 and 4), two women had liquid stool leakage (score 1 and 2) and two women had solid stool incontinence (both score of 1). Nine women were not sexually active; of the remaining 57 women, 7 complained of slight dyspareunia. Sixteen women had delivered babies since surgery. Caesarean section was performed in three women and the rest had vaginal deliveries. One woman had twins delivered vaginally and complained of recurrence of her perineal body tear, with a CCIS of 8 . Four women were pregnant at time of follow-up.

Thirty-six women were available for 3-year follow-up. CCIS of 0 was given by 29 women. The remaining seven women had scores ranging from 1 to 3 . Five women had liquid stool leakage (scores 1, 1, 1, 1, 2). No one complained of solid stool leakage. Seven women had subsequent vaginal deliveries and had CCIS of 0 . Thirty-one women were sexually active and two complained of mild dyspareunia.

At 4 years following surgery, 30 women were able to be contacted. Twenty-five (83\%) had a CCIS score of 0 . Five women scored $>0$ with a range of $1-9$. Three women complained of flatal incontinence (scores 2, 2, 2), three women had liquid stool leakage (scores $1,1,2$ ) and one had solid stool leakage (score 2). Of the 30 women, 27 were sexually active and 2 complained of slight dyspareunia. Since the 2year follow-up, eight other women had babies, six by caesarean section and two vaginal deliveries (1 woman had delivered 2 children since surgery). There was no worsening of anal continence after vaginal delivery. One woman was pregnant at the time of interview and another had suffered a miscarriage.

Twenty-one women were able to be contacted for 5-year follow-up. Of these women, 18 had a CCIS of 0 . No woman complained of solid faecal incontinence. Three women complained of flatal incontinence (scores 1,2,2) and 3 of liquid stool leakage (scores $1,1,2$ ). One woman did not have a partner; of the remaining 20 women, 1 complained of dyspareunia. Seven women had vaginal deliveries without compromising anal function.

At 6 years, six women were able to be contacted. Three women had a CCIS of 0 , two women complained of liquid stool leakage and the remaining woman stated that she had recurrence of perineal tear following a subsequent vaginal delivery (score 6).

At 7 years, six women were contacted and another's relatives informed us that she had died. Four women had a CCIS of 0 and the remaining two women complained of flatal incontinence (score 2,2). Five women were sexually active without pain. Two women had subsequent vaginal deliveries without affecting their anal continence.

\section{Discussion}

Fourth-degree tears involve injury to the perineal body, anal sphincter complex and anorectal mucosa. In these lowresource areas, the perineal tears are not sutured and heal by secondary intention. The fusion of the torn edges of the vagina and anorectal tissues results in a total perineal defect [7] with absent perineal body and complete separation of the anal sphincters. Apart from the effects on anal continence, unrepaired fourth-degree tears have been shown to cause social stigmatization and abandonment of these women by their husbands and families [15] and mental health dysfunction [16].

Most of the women (55.3\%) with chronic fourth-degree tears stated that the antecedent event was their second or subsequent deliveries. This is in contrast to other studies $[2,3,6]$ on acute OASIs (including fourth-degree tears) where the majority are primiparous women. In high-resource areas, women with OASIs often elect to have caesarean sections for their subsequent deliveries but this would not explain the higher rates of fourth-degree tears in the multiparous women in our study. It may be that in subsequent deliveries, the babies are larger and hence there is a higher risk of perineal body injury. A study reviewing over 11,000 deliveries demonstrated 6 $(40 \%)$ of the 15 women reporting fourth-degree tears were 
multiparous [6]. In this same study, it was noted that acute fourth-degree tears contributed to a larger percentage $(8.1 \%)$ of all OASI in multiparous compared to $4.9 \%$ of all primiparous OASI [6].

This technique for the repair of the chronic fourth-degree tear has demonstrated low postoperative complication rates [14]. It is also useful in low-resource areas as no flaps are utilized as these may increase the risk of postoperative complications. The unrepaired obstetric injuries result in fusion of laterally displaced tissues, and thus mobilization and repair are required. We believe that flaps are not necessary as there is no loss of tissue. In a previous study of 61 women with chronic fourth-degree tears, $100 \%$ reported a CCIS of 0 at 4-6 week follow-up and 8 of the $9(88.9 \%)$ women at 12 months had a CCIS of 0 and the other woman had a score of 9 , with flatal incontinence being the predominant symptom [14].

In the follow-up of 101 women presented in this study, 88 (87\%) had a CCIS of 0 at 12 months, which is similar to the small cohort in the previous study [14]. Of women who were sexually active, the preoperative dyspareunia rate of the 214 women was $58.8 \%$, again similar to the small cohort of women presented previously [14]. At 12 months postoperatively, 9 of the $82(11 \%)$ women who were sexually active complained of dyspareunia. The reasons for the reduction of dyspareunia may be the women's perception of a better body image or being more at ease without trying to hide the condition from thier partners.

Results from follow-up at 1 to 7 years are encouraging although numbers were reduced with increasing years of follow-up. It appears that most women who had a vaginal delivery did not complain of worsening of their CCIS apart from the women who suffered recurrent OASIs. This appears consistent with other authors with short-term follow-up after OASIs repair [17]. In the follow-up of our women over the 7 years, there were 42 babies delivered with 9 caesarean sections and the remaining had vaginal deliveries (including 1 set of twins). Two women reported recurrence of the fourthdegree tear.

Longer term follow-up of women in low-resource communities has been challenging. The women are often illiterate and no postal services are available in their villages. Returning for follow-up can be difficult because of transportation costs, deficiencies in infrastructure/roads and lack of transportation in remote areas. The subordinate position of women in society also adds to the difficulty for follow-up as a woman may not attend if her husband or family does not give permission. Women are usually contacted by their mobile telephones. In a poverty-stricken area with lack of mains electricity, there is often no credit for the mobile phones or, if the telephone is not charged, then contacting the women is not possible.

Personal safety may contribute as an obstacle to follow-up. There was a massacre in the Kasese District at the end of 2016, and we are uncertain if any of the women in this study were affected or lost their telephones during the chaos and hurry for safety. In addition, there was the Ebola outbreak (2018/19) in eastern DR Congo with Kagando only $18 \mathrm{~km}$ from the eastern DR Congo border. In 2020, there were massive floods in the Rwenzori and Kasese areas with many villages, houses and even a hospital severely affected or washed away. Coronavirus also affected the area as it did in most parts of the world. We suspect that these disasters have affected our follow-up.

In conclusion, surgery for unrepaired fourth-degree obstetric perineal tears (total perineal defects) can be performed in low-resource areas without the use of diversions or flaps/ grafts. Short- and medium-term follow-ups are encouraging.

Authors contributions J Goh: project development, manuscript writing. H Natukunda: data collection, data analysis.

I Singasi: data collection, data analysis.

E Kabugho: data collection.

H Krause: project development, manuscript editing.

A Browning: data collection, manuscript editing.

\section{Declarations}

Conflict of interest None.

\section{References}

1. Power D, Fitzpatrick M, O'Herlihy C. Obstetric anal sphincter injury: how to avoid, how to repair: a literature review. JFP. 2006;55: 193-200.

2. Marsh F, Rogerson L, Landon C, Wright A. Obstetric anal sphincter injury in the UK and its effect on bowel, bladder and sexual function. Eur J Obstet Gynecol Reprod Biol. 2011;154:223-7.

3. Groutz A, Cohen A, Gold R, Hasson J, Wengier A, Lessing JB, et al. Risk factors for severe perineal injury during childbirth: a case-control study of 60 consecutive cases. Color Dis. 2011. https://doi.org/10.1111/j.1463-1318.2011.02620.x.

4. Kumar R. Anal incontinence and quality of life following obstetric anal sphincter injury. Arch Gynecol Obstet. 2012;285:591-7.

5. Lindqvist $\mathrm{P}$, Jernetz $\mathrm{M}$. A modified surgical approach to women with obstetric anal sphincter tears by separate suturing of external and internal anal sphincter. A modified approach to obstetric anal sphincter injury. BMC Pregnancy Childbirth. 2010;10:51.

6. Ramalingam K, Monga AK. Outcomes and follow-up after obstetric anal sphincter injuries. Int Urogynecol J. 2013;24:1495-500.

7. Goh J, Romanzi L, Elneil S, Haylen B, et al. An international continence society (ICS) report on terminology for female pelvic floor fistulas. Neurol Urodybam. 2020. https://doi.org/10.1002/nau. 24508.

8. Hollingshead JRF, Warusavitarne J, Vaisey CJ, Northover JMA. Outcomes following repair of traumatic cloacal deformities. Br J Surg. 2009;96:1082-5.

9. Venkatesh KS, Ramanujam P. Surgical treatment of traumatic cloaca. Dis Colon Rectum. 1996;39:811-6.

10. Abcarian H, Orasy CP, Pearl RK, Nelson RL, Briley SC. Traumatic cloaca. Dis Colon Rectum. 1989;32:783-7. 
11. Altomare DF, Rinaldi M, Bucaria V, Marino F, Lobascio P, Sallustio PL. Overlapping sphintroplasty and modified lotus petal flap repair of traumatic cloaca. Tech Coloproctol. 2007;11:268-70.

12. Kaiser AM. Cloaca-like deformity with faecal incontinence after severe obstetric injury - technique and functional outcome of anovaginal and perineal construction with $\mathrm{X}$-flaps and sphincteroplasty. Color Dis. 2008;10:827-32.

13. Valente MA, Khanduja KS. Layered surgical repair of traumatic cloacal deformities: technical details and functional outcomes. Tech Coloproctol. 2012;16:153-6.

14. Goh JTW, Tan SBM, Natukunda H, Singasi I, Krause HG. Outcomes following surgical repair using layered closure of unrepaired 4th degree perineal tear in rural western Uganda. Int Urogynecol J. 2016;27(11):1661-6. https://doi.org/10.1007/ s00192-016-3024-6.

15. Krause HK, Natukunda H, Singasi I, Hicks SSW, Goh JTW. Treatment seeking behaviour and social status of women with pelvic organ prolapse, $4^{\text {th }}$ degree tears and obstetric fistula in western Uganda. Int Urogynecol J. 2014;25:1555-9. https://doi.org/10. 1007/s00192-014-2442-6.

16. Krause HG, Hall BA, Ng SK, Natukunda H, Singasi I, Goh JTW. Mental health screening in women with severe pelvic organ prolapse, chronic fourth-degree obstetric tear and genital tract fistula in western Uganda. Int Urogynecol J. 2017;28:893-7. https://doi.org/ 10.1007/s00192-016-3177-3.

17. Jordan PA, Naidu M, Thakar R, Sultan S. Effect of subsequent vaginal delivery on bowel symptoms and anorectal function in women who sustained a previous obstetric anal sphincter injury. IUGJ. 2018. https://doi.org/10.1007/s00192-018-3601-y.

Publisher's note Springer Nature remains neutral with regard to jurisdictional claims in published maps and institutional affiliations. 